\title{
Quantification and evolution of mitochondrial genome rearrangement in Amphibians
}


Shoubao Yan ${ }^{1}$, Chengrun Wang ${ }^{1}$, Xianzhao Kan ${ }^{2^{*}}$ and Liuwang $\mathrm{Nie}^{2^{*}}$

\begin{abstract}
Background: Rearrangement is an important topic in the research of amphibian mitochondrial genomes ("mitogenomes" hereafter), whose causes and mechanisms remain enigmatic. Globally examining mitogenome rearrangements and uncovering their characteristics can contribute to a better understanding of mitogenome evolution.

Results: Here we systematically investigated mitogenome arrangements of 232 amphibians including four newly sequenced Dicroglossidae mitogenomes. The results showed that our new sequenced mitogenomes all possessed a trnM tandem duplication, which was not exclusive to Dicroglossidae. By merging the same arrangements, the mitogenomes of $\sim 80 \%$ species belonged to the four major patterns, the major two of which were typical vertebrate arrangement and typical neobatrachian arrangement. Using qMGR for calculating rearrangement frequency (RF) (\%), we found that the control region $(C R)(R F=45.04)$ and $\operatorname{trn} L 2(R F=38.79)$ were the two most frequently rearranged components. Forty-seven point eight percentage of amphibians possessed rearranged mitogenomes including all neobatrachians and their distribution was significantly clustered in the phylogenetic trees $(p<0.001)$. In addition, we argued that the typical neobatrachian arrangement may have appeared in the Late Jurassic according to possible occurrence time estimation.
\end{abstract}

Conclusion: It was the first global census of amphibian mitogenome arrangements from the perspective of quantity statistics, which helped us to systematically understand the type, distribution, frequency and phylogenetic characteristics of these rearrangements.

Keywords: Mitogenomics, Amphibians, qMGR, Rearrangement score, Rearrangement frequency, Phylogenetic characteristics

\section{Background}

As semi-autonomous organelles, mitochondria retain their own genomes and participate in many essential biological processes in eukaryotic cells such as energy

\footnotetext{
*Correspondence: jifengzhang@fudan.edu.cn; xianzhao@ahnu.edu.cn; Iwnie@mail.ahnu.edu.cn

${ }^{1}$ School of Biological Engineering, Huainan Normal University, Huainan, Anhui 232001, People's Republic of China

${ }^{2}$ College of Life Science, Anhui Normal University, Wuhu, Anhui 241000,

People's Republic of China

Full list of author information is available at the end of the article
}

transduction and intermediary metabolism. The content of vertebrate mitogenomes is conservative, including 13 protein-coding genes (PCGs), 22 tRNA genes (trns), 2 rRNA genes (rrns) and a control region (CR) with replication and gene transcriptional regulatory signals [1, 2]. Because of the moderate evolutionary rate of the mitogenome, it has been an excellent molecular marker for phylogenetic studies [3-6].

The gene order of vertebrate mitogenomes is as conservative as its content, such that human, mouse, clawed frog and zebrafish all share the same gene arrangement 
in their mitogenomes [7-10]. However, with an increasing number of different species' mitogenomes completely sequenced, gene rearrangements have been reported in many different taxa. Generally, these rearrangements are inferred to the results from events such as gene transposition, gene inversion, gene duplication, and gene loss. Summaries and comparisons of animal mitogenome rearrangements have been reported $[3,11]$. An initial important study undertaken by Boore summarized all gene arrangements known for Metazoa, based on no more than 100 mitogenomes available at that time [1]. Further comparative studies of mitogenome arrangement have subsequently been published (e.g., [12-15]). In addition, several possible rearrangement models were proposed to explain mechanisms, including tandem duplicationrandom loss (TDRL) [16, 17], tandem duplication and non-random loss (TDNL) [18, 19], intramitochondrial recombination [20, 21], etc. Using the CREx and TreeREx programs, based on four rearrangement models, other studies have tried to find common intermediate steps (common intervals) in two or more gene orders being investigated to elucidate the evolution of mitogenome rearrangements in different lineages such as insects and crabs [22-25].

In general, most animals retain the conserved rather than rearranged mitogenome components and order. The conservative arrangement is called the "typical vertebrate (mitogenome) arrangement" in vertebrates and the "typical invertebrate (mitogenome) arrangement" in invertebrates $[1,26]$. To date, the number of vertebrate species with typical vertebrate arrangement accounts for more than half of all species for which mitogenomes have been determined. Among the amphibians, neobatrachians are the majority of frogs, accounting for $~ 92 \%$ of the total, over 6600 species (AmphibiaWeb, http://www.Amphi biaweb.org/, accessed February, 2020). Most sequenced neobatrachian frogs possess a derived mitogenome arrangement, "typical neobatrachian arrangement" [14, $27,28]$. Furthermore, there are some other types of rearrangements in addition to typical neobatrachian arrangement in amphibians. For example, the mitogenome of the neobtrachian frog Limnonectes bannaensis lacks $\operatorname{trn} A$, $\operatorname{trnN}, \operatorname{trn} C$ and $\operatorname{trnE}$ and contains a tandem duplication of trnM [29], the mitogenome of the caecilian Crotaphatrema lamottei includes the duplications of $\operatorname{trn} F, \operatorname{trn} P$ and $\operatorname{trnT}$ and lack of $\operatorname{trnK}$ [30], and there are two CRs found in the mitogenomes of the neobatrachian frogs Mantella madagascariensis [31] and Rhacophorus schlegelii [32]. In addition, while nad6 is located between nad5 and cob genes within typical vertebrate mitogenome, it is rearranged to between $r r n L$ and $n a d 1$ in the mitogenome of the plethodontid salamander Aneides hardii [33]. Furthermore, in some amphibians intraspecific variation in mitogenome rearrangements has been reported [34]. These findings inspire us to further explore the landscape of mitogenome rearrangements in amphibians.

Except for earlier studies on a few species of amphibians, most studies have focused only on a few lineages rather than a more global and systematic analysis. Also, previous studies have paid little attention to the role of individual genes in rearrangement. Recently we proposed a method, qMGR, for quantifying mitogenome rearrangement and developed a web service (http://qmgr. hnnu.edu.cn/) that provides large-scale and accurate analysis of mitogenome rearrangement information [35].

In this study, we newly determined mitogenomes for four frogs in the neobatrachian frog family Dicroglossidae, and found that they all had a tandem duplication of trnM (IQMM trn cluster), which was not a feature exclusive to this family $[36,37]$. To identify common characteristics of mitogenome rearrangement in amphibians, we then focused on the study of gene rearrangement patterns of all known amphibian mitogenomes, quantified the rearrangement frequency $(R F)$ for each single gene and the rearrangement score (RS) for each mitogemome by qMGR, detected phylogenetic characteristics of species with identical mitogenome arrangements, and estimated possible time for rearrangement patterns. Our findings contribute to understanding characteristics and evolution of mitogenome rearrangement in amphibians.

\section{Results}

\section{trnM tandem duplication of amphibian mitogenomes}

Lengths of the four newly sequenced mitogenomes are 18,520 bp (Quasipaa robertingeri), 16,640 bp (Limnonectes fragilis), 18,154 bp (Limnonectes fujianensis (Taiwan)) and 18,293 bp (Limnonectes fujianensis (Fujian)), respectively, and the full range of their GC contents was relatively narrow (39.7-42.9\%). The four new mitogenomes all contain a tandem duplication of trnM (IQMM trn cluster) that also occurs in other sequenced dicroglossids [14].

Among the 35 amphibian mitogenomes presenting evidence of duplication or loss of genes as well as CRs (excluding gene rearrangement with the same total number of genes), 19 species (including our four new mitogenomes) possess a tandem duplication of trnM (IQMM trn cluster) (see Table 1). These 19 species represent 16 species of Dicroglossidae, two species of Megophryidae (the non-neobatrachian frog family), and one species of the neobatrachian Ceratobatrachidae. Thus, tandem duplication of trnM is not exclusive to Dicroglossidae, and more than one rearrangement event is required to explain this pattern given that these families are distantly related to each other $[38,39]$. The frogs Leptolalax oshanensis (I-Q- $\underline{\mathrm{M}}-\mathrm{V}-\mathrm{P}-\underline{\mathrm{M}}-\mathrm{nad} 2$ ) and Mantella 
Table 1 List of amphibian mitogenomes with two trnM genes in this study

\begin{tabular}{|c|c|c|}
\hline Species & Taxon & Accession Nos \\
\hline Platymantis vitianus & Anura; Ceratobatrachidae & NC_027671 \\
\hline Euphlyctis hexadactylus & Anura; Dicroglossidae & NC_014584 \\
\hline Fejervarya cancrivora & Anura; Dicroglossidae & NC_012647 \\
\hline Fejervarya limnocharis & Anura; Dicroglossidae & NC_005055 \\
\hline Hoplobatrachus rugulosus & Anura; Dicroglossidae & NC_019615 \\
\hline Hoplobatrachus tigerinus & Anura; Dicroglossidae & NC_014581 \\
\hline Nanorana parkeri & Anura; Dicroglossidae & NC_026789 \\
\hline Nanorana pleskei & Anura; Dicroglossidae & NC_016119 \\
\hline Nanorana taihangnica & Anura; Dicroglossidae & NC_024272 \\
\hline Occidozyga martensii & Anura; Dicroglossidae & NC_014685 \\
\hline Quasipaa boulengeri & Anura; Dicroglossidae & NC_021937 \\
\hline Quasipaa robertingeri & Anura; Dicroglossidae & this study \\
\hline Quasipaa spinosa & Anura; Dicroglossidae & NC_013270 \\
\hline Quasipaa yei & Anura; Dicroglossidae & NC_024843 \\
\hline Limnonectes bannaensis & Anura; Dicroglossidae & AY899242 \\
\hline Limnonectes fragilis & Anura; Dicroglossidae & this study \\
\hline Limnonectes fujianensis (Fujian \& Taiwan) & Anura; Dicroglossidae & this study \\
\hline Mantella madagascariensis* & Anura; Mantellidae & NC_007888 \\
\hline Leptobrachium boringii & Anura; Megophryidae & NC_024427 \\
\hline Leptolalax oshanensis* & Anura; Megophryidae & NC_020610 \\
\hline Oreolalax major & Anura; Megophryidae & NC_030605 \\
\hline
\end{tabular}

* All species with two trnM are tandem duplication except Leptolalax oshanensis and Mantella madagascariensis

madagascariensis (nad5-I- $\underline{\mathrm{M}}-\mathrm{L} 2-\mathrm{P}-\mathrm{F}-r r n S-\mathrm{V} 1-r r n L-\mathrm{L} 1-$ T-nad1- $\underline{\mathrm{M}}$-CR) have two separate copies of trnM rather than a tandem duplication (Additional file 1: Table S1). The difference in position suggests that they may possess different mechanisms of occurrence [29, 31]. The amphibian species with gene duplication or loss (involved with other tRNA genes, rRNA genes, PCGs and CRs) are also shown in Additional file 1: Table S1.

\section{Different patterns of mitogenome rearrangement in amphibians}

We subsequently investigated more rearrangement types of 232 amphibian complete mitogenomes filtered by available annotation information. Among them, 121 species' mitogenomes represented typical vertebrate arrangement, and the remaining 111 species possessed 43 types of gene arrangement, when we examined the arrangements of all mitochondrial $(\mathrm{mt})$ genes involved, which were defined as global arrangement. Their arrangements were summarized in Additional file 1: Figure S1. However, ignoring the species with rare arrangements (only one or two occurrences), they all belonged to major arrangements that occurred at least three times (irrespective of phylogeny) in amphibian mitogenomes, as shown in Fig. 1a. In the figure, there were only four patterns in these global arrangements. We labeled them as Patterns $1 \sim 4$ in descending order of the frequency of rearrangement types. And we identified two segments that were subject to highly frequent rearrangements as Region 1 and Region 2, respectively. Between them, Region 1 covered the nad5-nad6-cob gene cluster and CR, and Region 2 was mainly composed of IQM trn cluster and WANCY trn cluster. Compared with typical vertebrate arrangement (Pattern 1), 55 neobatrachians shared the second most frequent pattern of mitogenome arrangement, known as typical neobatrachian arrangement, which had an LTPF trn cluster in their Region 1, and we found that all neobatrachians belonged to Pattern 2. Due to the existence of novel IQMM trn cluster in Region 2, the six species of Dicroglossidae including the new mitogenomes determined were distinguished from typical neobatrachian arrangement and formed a new pattern, Pattern 3. Pattern 4 occurred in three species of the genus Odorrana, whose HLTPF trn cluster replaced LTPF trn cluster of neobatrachians in Region 1.

PCGs play an important role in mitogenome rearrangement in vertebrates $[40,41]$. To reduce the complexity of mitogenome rearrangement caused by RNA genes and CRs, we further investigated the local arrangement (not all genes involved) limiting analyses on only PCGs. Figure 1b shows the 3 patterns (Pattern 1 3) of PCGs arrangements (frequency $\geq 3$ ), which only the frog 


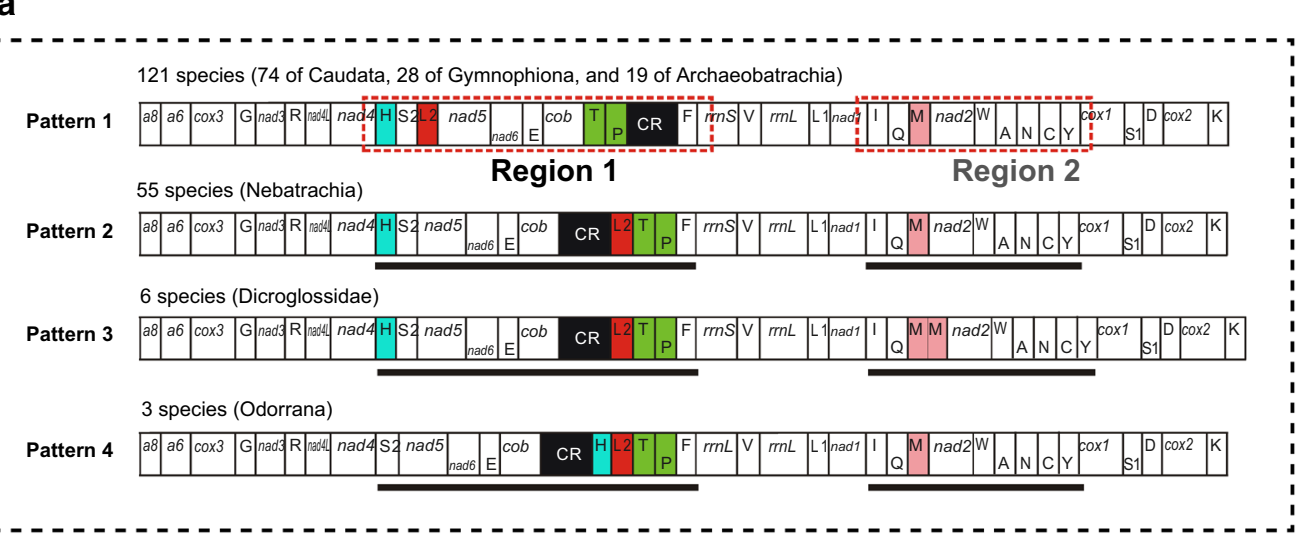

Global arrangement (all genes)

b



Local arrangement (PCGs)

\section{d}

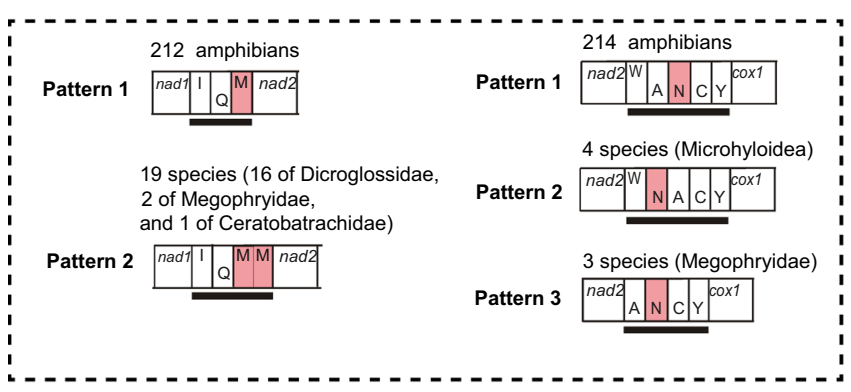

Local arrangement (Region 2)

\section{C} 126 species (77 of Caudata, 30 of Gymnophion and 19 of Archaeobatrachia)

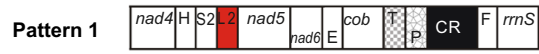

62 species (Nebatrachia)

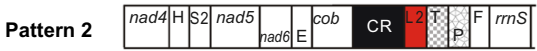

3 species (Megophryidae)

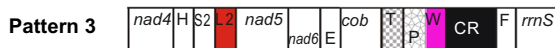

3 species (Fejervarya)

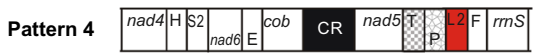

3 species (Odorrana)

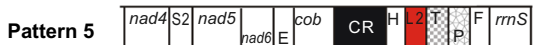
'

Local arrangement (Region 1)

Fig. 1 The patterns of global and local mitogenome arrangement in amphibians (occurrence frequency $\geq 3$ times among sampled taxa). The number of occurrences and categorization are shown above each illustration of patterns, main rearranged genes or regions are marked with color, red dashed box or underline). a Global arrangement patterns involved with all mt genes. b Local arrangement patterns only involved with PCGs. c Local arrangement patterns in Region 1. d Local arrangement patterns of IQM region and WANCY region in Region 2. Abbreviations of mt genes follows ref. [14]

Hoplobatrachus rugulosus, a species with double mitochondrial nad5 genes (only present once among sampled amphibians) was excluded. Among them, $91.3 \%$ of the sampled amphibians shared the first pattern (Pattern 1) of PCGs arrangement, while the other 19 species from Anura and Caudata belonged to the remaining two patterns, implying that the probability of rearrangement involved proteins is much smaller than other genes. The major differences among the 3 patterns related to the gene orders of nad5, nad6, and cob. Therefore, we considered that the nad5-nad6-cob segment may be "an active region" of $\mathrm{mt}$ PCGs rearrangement, and the segment was defined as Region 3.

Figure 1c and $\mathrm{d}$ show the patterns of mitogenomic local arrangements that occurred at least three times in Region 1 and Region 2, respectively. The Region 1 of 
Fig. 1c included two extra trn clusters: a TPW trn cluster at the $5^{\prime}$ end of CR and a TPLF trn cluster at the $3^{\prime}$ end of $\mathrm{CR}$, which was derived from 3 species of Megophryidae and 3 species of genus Fejervarya, respectively, compared with Fig. 1a of mitogenomic global arrangements. The left part of Fig. 1d shows that a novel local arrangement, the IQMM trn cluster, was derived from 19 species out of 3 families (all within Anura), namely Dicroglossidae, Megophryidae, and Ceratobatrachidae (see also results of trnM tandem duplication above). Similarly, we also found other rearrangement patterns in the WANCY region of Region 2, the pattern of 'WNACY' was present in 4 species of Microhyloidae and the pattern of 'ANCY' was present in 3 species of Megophryidae (whose mitogenome possessed the TPW trn cluster).

Compared to major arrangements, 47 species with rare arrangements accounted for $42.3 \%$ of all rearranged amphibian mitogenomes including 7 pairs of species with double rearrangements (the same rearrangement type appeared only twice in all sampled species) and 33 species with single rearrangement (this rearrangement type is unique in all sampled species) (Fig. 2).

\section{Accurate quantification of rearrangement frequency}

qMGR [35] is a method for large-scale and rapid quantification of mitochondrial genome rearrangements. Compared with the arrangement of the reference genome, it can calculate the rearrangement score $(R S)$ of each gene in each genome one by one based on the changes of genes on its both sides, and accumulate $R S$ of all genes in this genome to obtain the genome's $R S$. In a given taxonomic group, dividing the actual $R S$ of a gene by its maximum possible $R S$ can be used to extrapolate the relative rearrangement frequency $(R F)$ of the individual gene. qMGR was used to accurately calculate the $R F$ of amphibian mitochondrial genes. Figure $3 \mathrm{a}$ and $\mathrm{b}$ show the $R F$ distributions of all individual genes of amphibians and their three consistent orders, respectively. As shown in Fig. 3a, $R F$ of most genes were less than 10 (\%), the genes with high $R F$ (\%, coloring deeper) were mainly concentrated in the nad5-CR segment and IQM-WANCY segment (namely, Region 1 and Region 2 mentioned above), consistent with previous findings for rearrangement hotspots in vertebrate mitogenomes [16, 42]. For each single gene, $C R$ was assigned the highest $R F(\%)$ with a score of



Fig. 2 Scatter plot of RS of species with rare arrangements (Single rearrangement and Double rearrangements). The red dotted line represents the average RS of 47 species with rare arrangements; The black dotted lines indicate RS of species belonging to four major patterns (global arrangement). The figure also shows the species with the highest and the lowest $R S$ and their rearrangement information, and the names of genes with two changed flanking genes are marked in red, the names of genes with changes of one-sided gene are marked in purple 

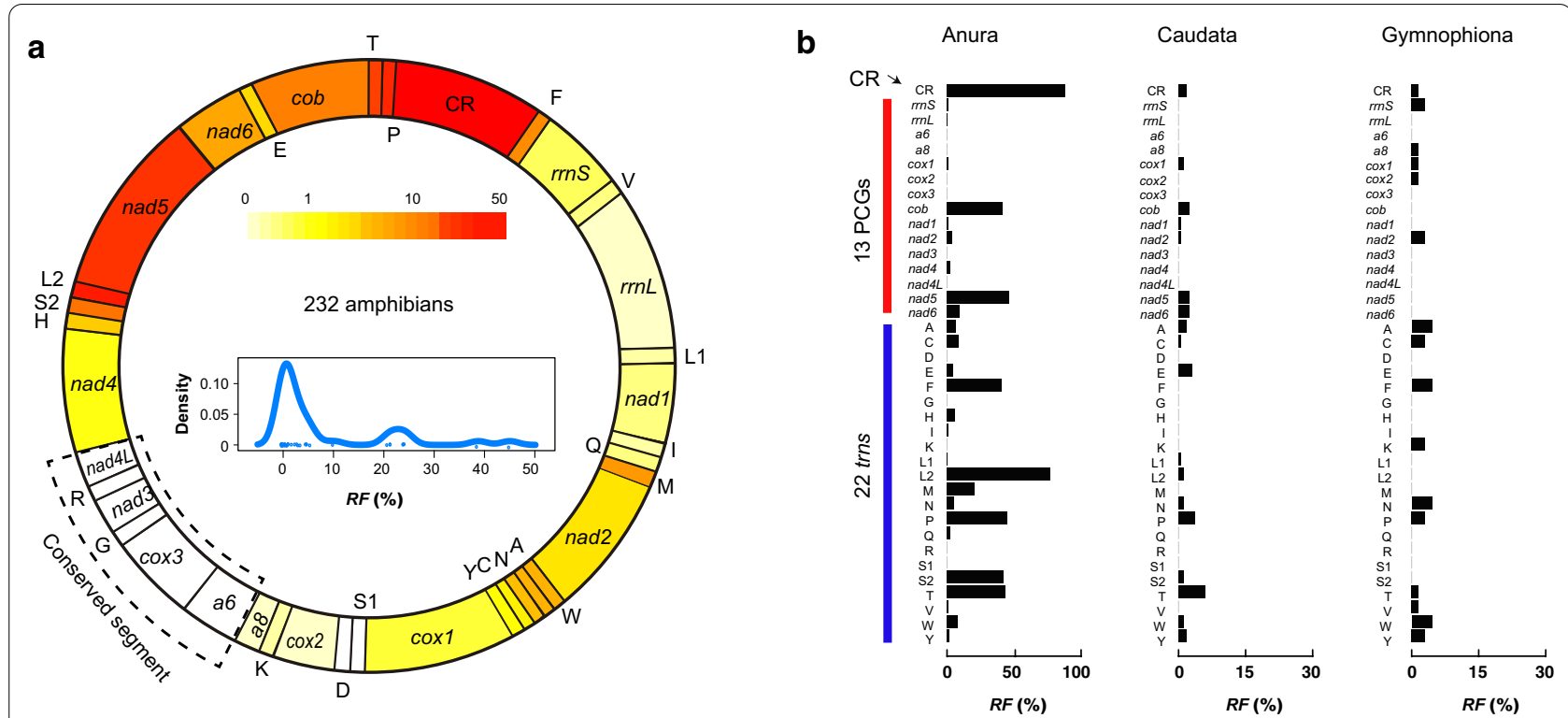

Fig. 3 RF distributions of mt genes of all sampled amphibians (a) and species of three orders (b) using the qMGR method. In (a), the outer ring shows the mitogenome arrangement of most amphibians (namely, typical vertebrate arrangement). Linear density distribution is in its inner bottom part, and the depth of colors corresponding to the different values of RF are placed in its inner upper part, and the higher the value, the darker the color. The control region (CR) and trnL2 gene are the two most frequently rearranged components. We also mark three or more contiguous conserved genes with RF of zero by dotted lines; In (b), the histograms indicates that RF of each gene in three separate groups: frogs, caecilians, and salamanders

45.04 by using qMGR [35], indicating that about $45 \%$ of the flanking genes of CR have been changed, that is, the changes have been accumulated more than 200 times (trnP and $\operatorname{trn} F$ are located at the $5^{\prime}$ and $3^{\prime}$ end of CR, respectively). $\operatorname{trn} L 2$ was ranked second with a score of 38.79 , and nad5 had the highest $R F(\%)$ among all PCGs, with a score of 24.14. In addition, according to the definition of $R F$, if consecutive adjacent genes all have the smallest $R F$ value (here 0 ), we believed that they themselves formed a rearranged conserved segment in the mitochondrial genome. We identified the two most conserved segments in amphibian mitogenomes as atp6cox3-G-nad3-R-nad4L and S-D between cox1 and cox2.

In Fig. 3b, there were fewer genes with a non-zero $R F$ $(<50 \%)$ and with relatively low scores $(<15)$ in Caudata and Gymnophiona. In comparison, $R F$ of most genes (27 of the total 38) in Anura were greater than zero, and some of them were greater than 30 . The primary reason was that most species with rearranged mitogenomes belonged to typical neobatrachian arrangement in this group (56.3\%). Also, $R F$ of anuran $\operatorname{trn} L 2$ and CR were both greater than 50 , mainly due to the fact that their rearrangements were accompanied by $>50 \%$ changes in adjacent genes on both sides compared to typical vertebrate arrangement.

Considering that typical neobatrachian arrangement is the dominant gene order in frogs' mitogenomes, we also tried to choose it as the benchmark for calculating $R F$. The results showed that the genes with changed $R F$ were those rearranged genes relative to typical vertebrates arrangement (Fig. 4). Interestingly, all of their scores had declined, but the relative rank of their $R F$ changes little. The top 3 of them were both CR, trnL2, and nad5 in order, implying that they are the most active elements of mitogenome rearrangement in frogs.

To further investigate the rearrangement degree of species with rare arrangement, based on qMGR [35], we also calculated their species $R S$, which was the cumulative value of the rearrangement scores of all genes in the genome of a given species. As shown in Fig. 2, we found that the species with the highest $R S$ is the neobtrachian frog Platymantis vitianus (species $R S=32$ ), which had 17 genes involved in rearrangement compared with typical vertebrate arrangement. The species with the lowest scores, consisting of the salamander Tylototriton verrucosus, the salamander Rhyacotriton variegatus and the caecilian Boulengerula taitana (species $R S=2$ ), had only one rearranged gene, which was a tandem duplcation of $\operatorname{trnT}$, trnT, and trnP, respectively (Fig. 2). The average $R S$ of all species with rare arrangements was 12.9 , which was slightly higher than the species with typical neobatrachian arrangement (Patten 2). In addition, Fig. 2 also shows $R S$ of the species belonging to the other three global arrangement patterns. 


\section{Anura}

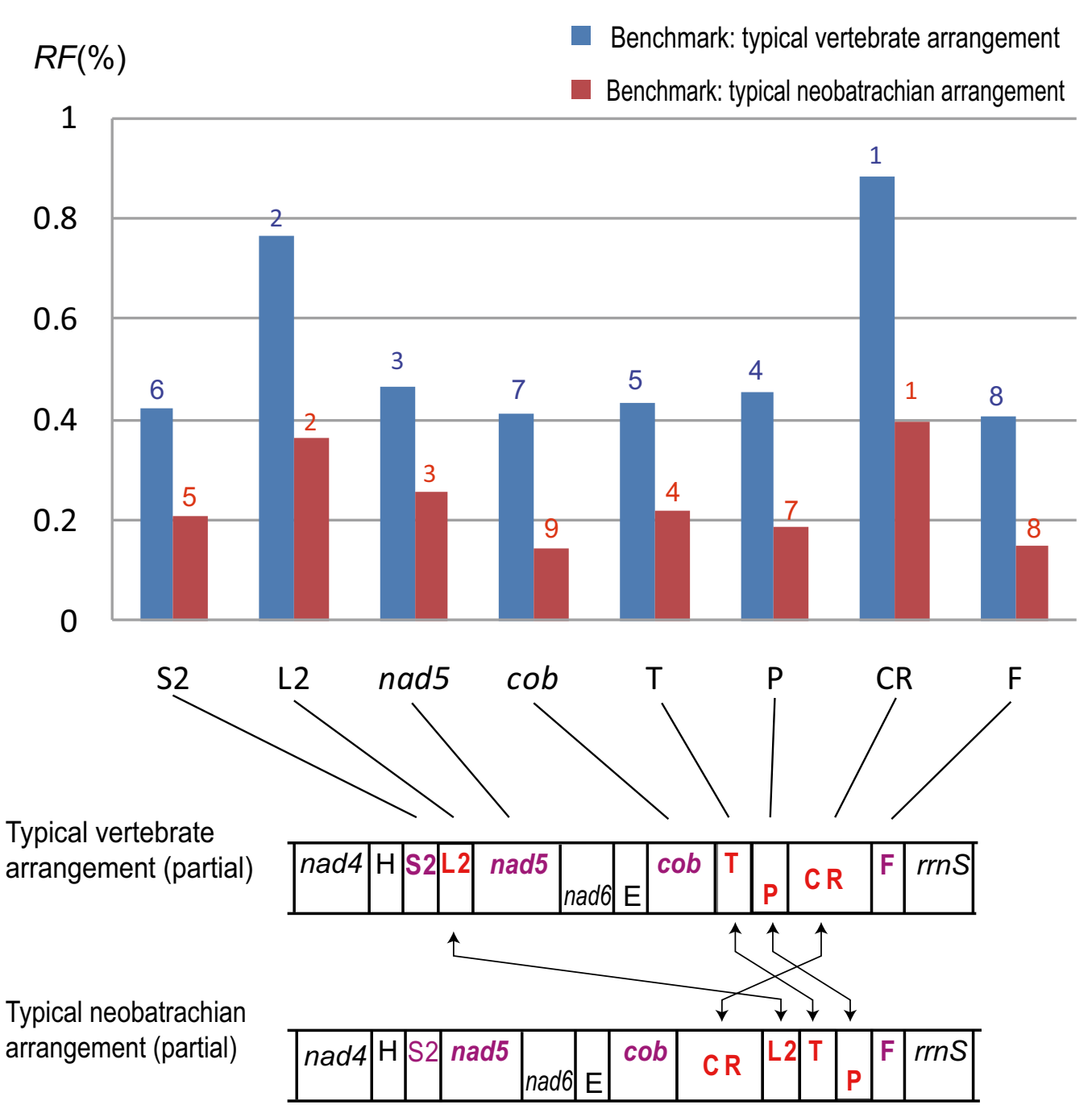

Fig. 4 Histogram of rearranged genes' $R F$ in anuran mitogenomes based on two different benchmarks, and comparison of two typical arrangements (partial) below it. In the figure above, the number above strips represents rank of RF of single gene in all genes sorted in descending order. In the segments rearranged of the figure below, and the color of the gene names represents the same meaning as in Fig. 2

\section{Phylogenetic characteristics of mitogenome rearrangement in amphibians}

For phylogenetic characteristics of rearranged amphibian mitogenomes, the optimal ML tree and BI tree of 232 amphibians were shown in Fig. 5 and Additional file 1: Figure. S2, respectively, and they had similar basic topologies. In them, the monophylies of the three amphibian groups (frogs, caecilians, and salamanders) were strongly supported, as found in most phylogenetic analyses [38, 43-46]. Within frogs, the relationship of two higherlevel groups, Neobatrachia and Archaeobatrachia (nonneobatrachian frogs) was consistent with most previous reports (e.g., [38, 44, 47, 48]). Overall support was high within all species. $84 \%$ of the nodes had a bootstrap value (BS) $\geq 75 \%$ (Fig. 5), and 98\% had Bayesian posterior probabilities (BPPs) $\geq 0.90$ (Additional file 1: Figure. S2). Our results suggested that the superfamily and family-level relationships of Neobatrachia were mostly consistent with most previous studies (i.e., superfamily Ranoidea includes Ranidae, Dicroglossidae, Microhylidae, Mantellinae, Rhacophoridae, etc.) [38, 44, 49, 50]. Additionally, BS and BPPs also strongly supported most families of salamanders and caecilians, for instance, Salamandridae, Plethodontidae, and Hynobiidae within Caudata [51], 


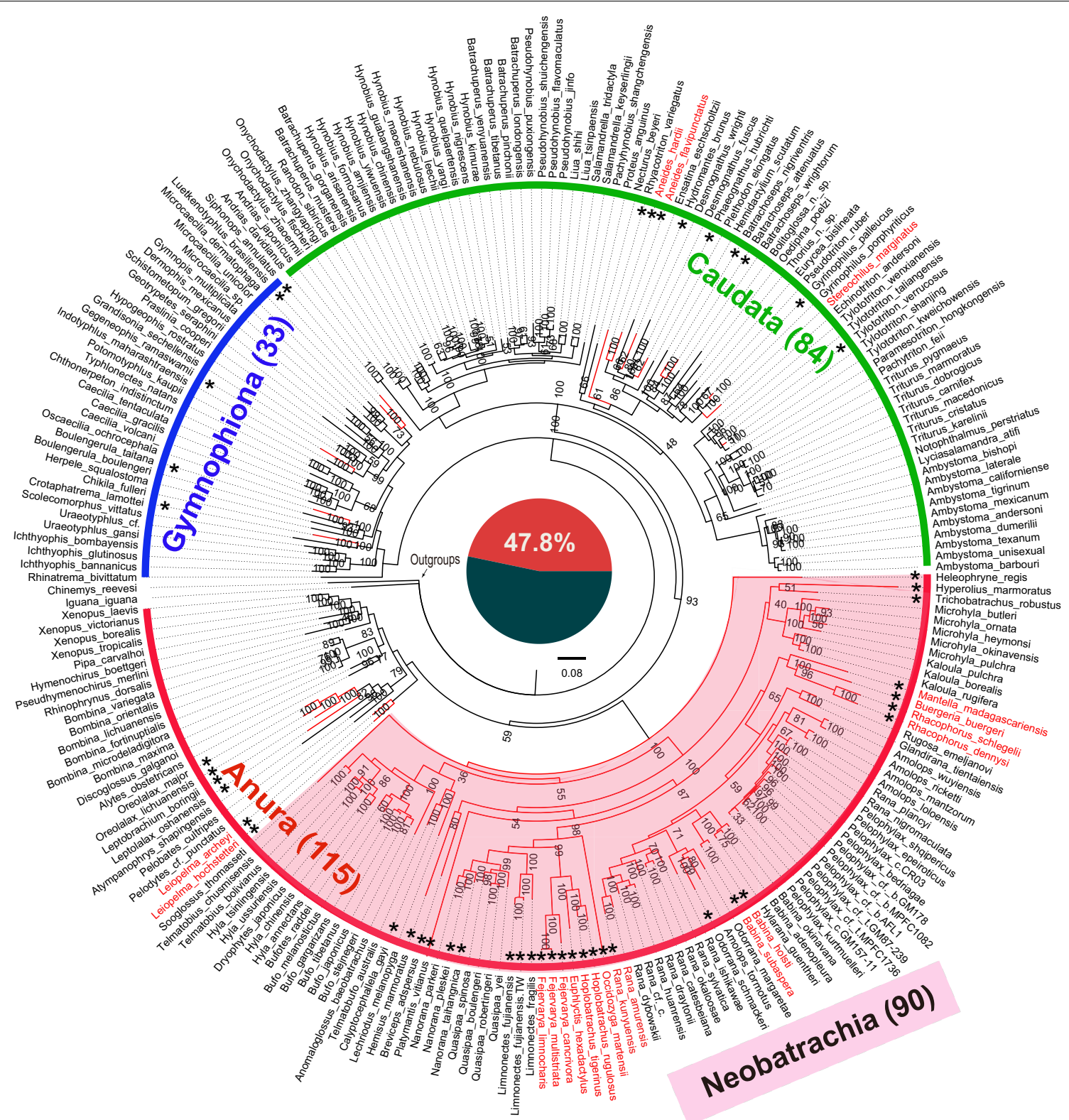

Fig. 5 Phylogenetic tree of all amphibians studied inferred using ML method based on the nucleotide dataset of $13 \mathrm{mt}$ PCGs. The tree divides extant amphibians into three major taxa (orders): Gymnophiona, Caudata and Anura (including Neobatrachia) and the number of sampled species are shown in brackets. We have marked the branches of the species with rearrangements and species names only involved with PCGs rearrangements in dark red, names of species with rare arrangement are marked with an asterisk, and a pale red background is given to Neobatrachia, the group with the most intensive rearrangements. The middle pie chart shows the proportion of sampled amphibian species with mt gene rearrangements

and Caeciliidae, Typhlonectidae, Ichthyophiidae within Gymnophiona [52].

Compared with other vertebrate taxa, mitogenome rearrangement of amphibians is seemingly more frequent [27], particularly in neobatrachian frogs [14, 28]. Among the 232 amphibian mitogenomes examined, there were 111 species $(47.8 \%)$ with non-typical organization (red branches marked in Fig. 5). In the 111 species with rearranged mitogenomes, only 15 species were members of the 117 total species sampled of Caudata (11.9\%) and Gymnophiona (15.2\%), while most of them were concentrated in Anura (83.5\%), especially Neobatrachia (90 species: $100 \%)$. Figure 5 also shows 20 species with rearrangements of PCGs (only the gene order of 13 PCGs in 
the mitogenome was considered), accounting for only 8.6\% of total species (red species name marked in Fig. 5). Species with rearranged mitogenomes tended to be phylogenetically clustered whether studied on all genes ( $\mathrm{p}<1.0 \mathrm{e}-10$, hypergeometric test) or PCGs $(\mathrm{p}<0.001$, hypergeometric test), suggesting that mitogenomic rearrangement of amphibians also possesses phylogenetic characteristics, similar with insects [22] and birds [53].

In Fig. 5, these species with rare arrangement were marked with asterisks. We found that they included $90 \%$ of the species with rearrangements of PCGs, which might be one of the reasons why their rearrangements were "rare". Among the 232 species examined, 28 species belong to 22 families, each of which includes only one or two species. We also further examined whether the rarity could be due to the density of taxon sampling. The result showed that it was highly dependent on density of taxon sampling ( $\mathrm{p}<1.0 \mathrm{e}-04$, hypergeometric test).

\section{Rearrangement time estimation of amphibian mitogenomes}

Because mitogenome rearrangement of amphibians possessed phylogenetic characteristics, and the same gene arrangement among different species was generally unlikely to be the result of convergent evolution [11], we could estimate the (latest) possible occurrence time of their pattern according to the divergence time of common ancestor lineages with the same rearrangement pattern. So we referred to the literature on divergence time of different taxa of amphibians [14, 39, 43, 45], and estimated the possible occurrence time of various patterns from three rearrangement enrichment regions, namely, Region 1, Region 2 and Region 3, as shown in Fig. 1.

Compared with the older Amphioxus (Branchiostoma floridae) mitogenome arrangement [54], the pattern of typical amphibian arrangement was consistent with that of vertebrates, including H-S2-L2-nad5-nad6-Ecob-T-P-CR-F (Region 1), IQM-nad2-WANCY (Region 2), and nad5-nad6-cob (Region 3). Different from their Region 3, the pattern, nad5-cob-nad6, were identified in 3 caudatans and 2 archaeobatrachians. It implied that the rearrangement pattern could have occurred before the divergence of frogs and salamanders, that is, it may be earlier than 350 million years ago (Ma) [39]. Four newly sequenced species of neobatrachians, and 2 archaeobatrachians, all had the IQMM pattern (IQMM trn cluster), suggesting that the pattern can appear earlier than $250 \mathrm{Ma}$, before the divergence of neobatrachians and archaeobatrachians in Anura [39, 43] (Additional file 1: Figure. S3). Similarly, the pattern, H-S2-nad5-nad6E-cob-CR-L2-T-P-F (from Region 1 of typical neobatrachian arrangement) may have existed in the Late Jurassic (earlier than $140 \mathrm{Ma}$ ) when neobatrachians appeared [14]. We also marked possible occurrence time of other rearrangement patterns in Additional file 1: Figure. S3.

According to the estimated time of the rearrangement patterns, as shown in the lower left corner of Additional file 1: Figure. S3, we speculated that the rearrangement of amphibian mitogenomes might present the following trends: (1) the trn genes near CR tended to be rearranged to the $3^{\prime}$ end of CR which was consistent with the transcription direction of protein-coding genes; (2) the $n d 5$ gene also had a tendency to rearrange to the $3^{\prime}$ end of CR.

\section{Discussion}

\section{Mitogenome rearrangement and qMGR method}

Just like our newly determined species, rearrangement events are often accompanied by related gene duplication as well as gene loss. Most existing models of rearrangement mechanisms often involve gene duplication and gene deletion (e.g. $[17-19,55,56]$,$) . Among these$ models, TDRL (tandem duplication-random loss) model has been widely accepted to explain the rearrangement mechanism of amphibian mitochondrial genomes[34], Such as Fejervarya limnocharis [57], L. bannaensis[29], Hoplobatrachus tigerinus [58], Leiopelma archeyi [59]. With TDRL model, Xia et al. [34] perfectly explained the rearrangement events within the species. TDNL (tandem duplication and non-random loss) is also another similar model involving gene duplication and gene loss, and it has been used to rationally explain the rearrangement of the millipedes (Narceus annularus and Thyropygus sp.) [18]. In addition, DMNR (the Dimer-Mitogenome and Non-Random Loss) and DRRL (the Double Replications and Random Loss) have also been proposed to explain the course of the rearrangement in two flatfish mitogenomes (Crossorhombus azureus and Samariscus latus) $[19,60]$.

Our research has found that trn genes were more prone to rearrangement than other genes, and some trn genes (such as $\operatorname{trnL2}$, $\operatorname{trn} T$, and $\operatorname{trn} P$ ) preferred to turn to the $3^{\prime}$ end of CR. Satoh et al. [61] proposed that there was a significant correlation between trn gene position (that is, trn gene order) and codon usage in vertebrate mitogenomes, and the closer to the $3^{\prime}$ end of CR the trn gene was, the higher its usage was, inferring that the mt gene arrangement of vertebrates is affected by translation constraints, which may help maintain the gene order for a long time. However, Xia et al. [28] claimed that the correlation was not significant for them of typical neobatrachian mitogenome. Furthermore, Xia et al. [34] also believed that the gene distributions of rearranged frogs were related to their non-adaptive forces. Therefore, the mechanism of trn gene order is still under debate in amphibian mitogenomes. 
Nevertheless, due to the relatively rarity of rearrangements and their constitution of useful synapomorphies, they may provide more useful information for phylogenetic inference with increasing difficulty of their own research [16, 28]. A large number of studies have been carried out to clarify possible units of rearrangement and possible evolutionary processes between two rearranged mitogenomes (e.g. [17, 22, 23, 29]). qMGR has more flexibility than other rearrangement analysis algorithms (e.g., CREx [25], TreeRex [62], amGRP [63] and GRAPPA [64]), and can analyze mitogenomes (or $\mathrm{mt}$ gene fragments) of different numbers and different rearrangement types, even other circular genomes such as chloroplasts. In the absence of prior knowledge, within a certain group, qMGR [35] was able to filter out highly rearranged genes and genomes, which would contribute to the study of the choice of rearrangement models and rearrangement pathways.

\section{Mitogenome rearrangement and phylogenetic analysis}

Many previous rearrangement studies were often accompanied by phylogenetic analysis (e.g., [14, 32, 34, 50]), which helped to speculate on the evolution of rearrangement events. In our study, we reconstructed two phylogenetic trees (BI tree and ML tree). We found that the phylogenetic relationship of most neobtrachians was consistent with previous studies (e.g., [38, 43, 44, 49, 65]), the relationship between teresomatans and all other caecilians was in full agreement with previous reports (e.g. [44, $49,52]$,), and our trees also supported a sister-group relationship between frogs and salamanders (the Batrachia hypothesis), as found in most previous studies(e.g. [44, $52,66]$,). In addition, the relationship between Leiopelmatidae and all other frogs was compatible with previous reports in BI tree (e.g. [50, 59, 67]). The sister relationships of Pipoidea and Discoglossoidea were consistently supported (BPPs $=1, \mathrm{BS}=83 \%$ ), however, some recent studies did not support the view (e.g. [38, 44, 50]). The inconsistent results may be affected by different species and selected molecular markers. But these subtle differences did not change the overall distribution of amphibian rearrangement types in the phylogenetic trees. Based on the results of the phylogenetic study above, species with the same pattern of mitogenome rearrangement mostly belonged to closely related taxa. Just like the previous reports of avian mitogenome rearrangement [53], the phylogenetic characteristics of rearrangement were further interpreted that they could originate from a common ancestor and were then retained during subsequent lineage diversification. Therefore, this makes it possible to use the divergence time of ancestral species with common mitogenome arrangement to estimate the occurrence time of rearrangement patterns.

\section{Non-coding regions of mitogenome rearrangement}

In the mitochondrial genomes, two non-coding regions, $\mathrm{CR}$ and $\mathrm{O}_{\mathrm{L}}$, play important roles in the rearrangement studies [16, 42]. The duplicated CR and mitochondrial gene rearrangement have been found in many parrot species [68]. Our study showed that CR was the most active element in the mitogenome rearrangement of amphibians. When we disregarded it in the study of PCGs rearrangements, the results may have missed some information. For example, nad6-cob-CR-nad5 of neobtrachian frog Buergeria buergeri [69] and nad6-cob-CR-nad5-CR of neobtrachian frog $R$. schlegelii [32] were treated as the same arrangement type.

Unfortunately, we found that a few species in the GenBank database have incomplete or even incorrect annotations for $\mathrm{O}_{\mathrm{L}}$ (as found by the references [70]). So we ignored this important element in the WANCY region, which was considered as a hotspot for rearrangement $[16,42]$. This made us unable to distinguish between $\mathrm{ACW}-\mathrm{O}_{\mathrm{L}}-\mathrm{NY}$ of marsupial Trichosurus vulpecula [71] and $\mathrm{A}-\mathrm{O}_{\mathrm{L}}-\mathrm{CWNY}$ of caecilian Siphonops paulensis [16], and between $\mathrm{WA}-\mathrm{O}_{\mathrm{L}}-\mathrm{NCY}$ and $\mathrm{WAN}^{-} \mathrm{O}_{\mathrm{L}}-\mathrm{CY}$ of neobtrachian frog $Q$. boulengeri (intraspecific rearrangement of mitogenome) [34]. These implied that the components examined in the study of gene rearrangements had a great influence on the results. In fact, some reports have found that $\mathrm{O}_{\mathrm{L}}$ is absent in birds, crocodiles, fish, scorpions, etc. [42, 72, 73]. However, in vertebrates with mitochondrial $\mathrm{O}_{\mathrm{L}}$, the WANCY region of amphibians possessed the most frequent rearrangements, which also involved gene duplication, gene loss, and pseudogenes (e.g., $[16,29,34$, $42,50])$.

\section{Conclusion}

In this study, we first examined the characteristics of trnM tandem duplication in four newly sequenced Dicroglossidae mitogenomes as well as in other amphibian taxa, and found that it was not an exclusive feature of Dicroglossidae. We then applied qMGR for calculating $R S$ and $R F$ of each single $\mathrm{mt}$ gene, and screened out high-frequency genes and conservative genes involved in different taxa of amphibian mitogenome rearrangement. Based on phylogenetic analysis, we found that mitogenomic rearrangement of amphibians possessed phylogenetic implications, and were concentrated in Neobatrachia. Still, typical vertebrate arrangement was the most dominant type of arrangements for amphibians. In addition, qMGR can also obtain $R S$ of species with rare arrangements, which can be used to measure the rearrangement degree of a single species. This was a systematic survey of the rearrangement of the amphibian mitochondrial genome and its evolution. Nevertheless, as the currently available data was less than $5 \%$ of the 
total number of known species, our results may still lack representativeness and integrity. More data and more indepth analysis will help us figure out thoroughly the rearrangement characteristics of amphibians.

\section{Methods}

\section{Determination and analysis of $\mathbf{4}$ new mitogenomes}

Samples of four dicroglossid frogs Q. robertingeri (code Zhang-YBJW031), L. fragilis (code DT-CP005), L. fujianensis (Taiwan population) (code Zhang-TWDT034) and L. fujianensis (Fujian population) (code DT-FJ002) were collected from Sichuan, Hainan, Taiwan and Fujian province in China, respectively. Total DNA was extracted from their fresh muscle tissues after the frogs were euthanized using $0.5 \% \mathrm{MS}-222$. Then tissues of the first two were stored at $-80^{\circ} \mathrm{C}$ at the College of Life Sciences, Anhui Normal University, China, and the latter two were stored at $-20^{\circ} \mathrm{C}$ at the School of Bioengineering, Huainan Normal University, China. In accordance with Regulation for the collection of genetic resources of China (HJ 628-2011), we collected all laboratory animals, and animal experiments and follow-up disposal were carried out based on Regulations for the management of laboratory animals in Huainan Normal University (2015). We designed multiple primer pairs (Additional file 1: word S1) based on sequence alignments of mitochondrial genes from closely related species [29, 57, 74], and carried out shotgun sequencing and assembling. We identified genomic components by the MITOS2 (http:// mitos.bioinf.uni-leipzig.de/index.py) [75], tRNAscan-SE (http://lowelab.ucsc.edu/tRNAscan-SE/) [76], and manual sequence comparison [2, 37]. Base composition was determined using DNASTAR (www.dnastar.com).

\section{Preparation of rearrangement data}

We downloaded sequences data of amphibian mitogenomes from NCBI: Organelle Genome Resource (http:// www.ncbi.nlm.nih.gov/genome/organelle/) on May 10, 2019. In total, we retrieved mitogenomes of 228 species (in addition to the four species newly sequenced here) by filtering out the data without complete annotation information. We then extracted location information of genes and their nucleotide sequences for subsequent rearrangement analysis and phylogeny using designed Perl and $\mathrm{R}$ scripts.

\section{Different rearrangement patterns}

To investigate major patterns of amphibian mitogenome rearrangement, we sorted all genes based on their position information in the genome. When starting with the same gene, we merged and counted species with identical gene orders. We defined the arrangement involved with all $\mathrm{mt}$ genes (37 genes + CR in this study) as a global arrangement, and those of not all genes were called local arrangements. We surveyed major arrangement whose the cumulative number with the same arrangements was $\geq 3$ times, For the type of arrangement less than or equal to two times, we called it "rare arrangement". We further subdivided the high-frequency rearrangement regions in the global arrangements or local arrangements into different regions, which also belonged to local arrangements. To facilitate research, we also numbered the different arrangement types of these major arrangements into multiple patterns.

\section{Precise quantification of rearranged genes and genomes} qMGR can be used to accurately calculate the rearrangement frequency of each single gene or each single genome within a given taxonomic group [35]. When a reference arrangement (benchmark) of mitogenome was selected, it can accumulate changes in genes at the two nearest flanking positions of a gene to be tested and give the gene a score. Based on this principle, qMGR can calculate the rearrangement score $(R S)$ of a complete mitogenome and the relative rearrangement frequency $(R F)$ of individual genes within a certain group (e.g., neobatrachians, anurans or amphibians) (referring to reference [35] and its website for more details on the method). We chose typical vertebrate arrangement as a benchmark for the comprehensive analysis of mitochondrial genome rearrangement in amphibians, and also chose typical neobatrachian arrangement for comparative analysis of $R F$. In the calculation process, we regarded the $C R$ as a single gene, while ignored pseudogenes and the origin of L-strand replication $\left(\mathrm{O}_{\mathrm{L}}\right)$ for their incomplete annotations.

\section{Phylogenetic analysis and rearrangement time estimation}

We performed phylogenetic analysis using maximum likelihood (ML) [77] and Bayesian inference (BI) [78] methods based on the combined nucleotide dataset of 13 PCGs of 232 species (including 43 families, about half of them contain only 1-2 species) as well as two outgroup species (turtle: Chinemys reevesi, NC_006082, and iguana: Iguana iguana NC_002793). Multiple sequence alignment was carried out using MAFFT 7.2 [79]. The substitution saturation analyses for each codon positions of each gene were assessed by using DAMBE 7.2.25 [80]. And we detected the saturation on their third codon positions. The information of substitution saturation for all codon positions of 13 genes could be seen in Additional file 1: Table S2. Therefore, phylogenetic analysis was only based on their first two codon positions. For BI analysis, the best schemes for partition and substitution models (Additional file 1: Table S3) were determined in PartitionFinder version 2.1.1 [81] according to the Bayesian 
Information Criterion (BIC) and greedy search algorithm. Then the BI analysis was implemented in MrBayes v.3.2.7a [82, 83]. We ran four Markov chains for $5 \times 10^{7}$ generations (sampling every 1000 generations) and calculated a 50\% majority-rule consensus tree and Bayesian posterior probabilities (BPPs) after discarding the initial $25 \%$ trees as burn-in. All MCMC runs were repeated twice to avoid spurious results. Furthermore, the convergence of the MrBayes analyses was checked with Tracer 1.7.1 [84]. Subsequently, the ML tree was inferred with RAxML v.8.2.12 [85] using the GTRGAMMA model, 100 starting trees and 1000 bootstrap replicates to assess node support [86]. After that, the ML bootstrap convergence test was carried out with parameter "-I autoMRE".

To estimate the possible occurrence time of gene rearrangement, we referred directly to the results of the studies on divergence time estimations [14, 39, 43, 45]. Based on the divergence timetable of amphibians and related taxa, we estimated the latest possible occurrence time of the different rearrangement patterns.

\section{Supplementary Information}

The online version contains supplementary material available at https://doi. org/10.1186/s12862-021-01755-3.

Additional file 1: Table S1. Amphibian species with mt gene duplication or loss in this study. Figure S1. Mitogenomic rearrangement patterns of all amphibian species investigated. The numbers in first column indicated the occurrence frequencies of patterns (a number less than three is defined as a rare arrangement in this study). Figure S2. Phylogenetic tree of all amphibians studied using BI method based on the nucleotide dataset of $13 \mathrm{mt}$ PCGs. The number of species sampled for each lineage is shown in brackets. We marked the branches of the species with $\mathrm{mt}$ gene rearrangements and the names of species only involved with PCGs rearrangements in dark red, and a pale red background was set on the branch of neobatrachians, the group with the most intensive rearrangements. Figure S3. Possible occurrence time and trends of local rearrangement patterns of mitogenomes according to divergence times of their ancestors. The possible trends were shown in the box at lower left. Word S1. Amplification scheme and primers sequences for sequencing four mitochondrial genomes in this study. Table S2. Determination of substitution saturation for each codon position of each gene. Table S3. The best partitioning scheme selected by PartitionFinder for different data matrices.

\section{Abbreviations}

a6, ATP6: ATP synthase subunit 6; a8, ATP8: ATP synthase subunit 8; Bl: Bayesian inference; BIC: Bayesian Information Criterion; BPPs: Bayesian posterior probabilities; cox 1-3, COX1-3: Cytochrome c oxidase subunit I-III; CR, D-loop: Control regions; cob, Cytb: Cytochrome b; IQM(M): $\operatorname{trn} I, \operatorname{trn} Q, \operatorname{trnM}(\operatorname{trnM}) ;$ LTPF: $\operatorname{trnL}(\mathrm{CUN}), \operatorname{trnT}$, trnP, and trnF; KS test: Kolmogorov-Smirnov test; Ma: Million years ago; ML: Maximum likelihood; $m$ t: Mitochondrial; nad1-6, 4L, ND1-6, 4L: $\mathrm{NADH}$ dehydrogenase subunit 1-6, 4 L; NJ: Neighbor-joining method; $\mathrm{O}_{\mathrm{L}}$ : The origin of light strand replication; PCR: Polymerase chain reaction; qMGR: Quantifying mitogenome rearrangements; RF: Rearrangement frequency; RS: Rearrangement score; TDRL: Tandem duplication and random loss; WANCY: $\operatorname{trn} W, \operatorname{trn} A, \operatorname{trn} N, \mathrm{OL}, \operatorname{trn} C$, and $\operatorname{trn} Y$; $\operatorname{tRNA}, \operatorname{trn}$ : Transfer ribonucleic acid; $\operatorname{trn} L$ 1: $\operatorname{trnL}(U \cup R) ; \operatorname{tCL2:~trnL~(CUN);~trnS1:~} \operatorname{trnS}(\mathrm{UCN})$; $\operatorname{trnS2}$ : $\operatorname{trn} S$ (AGY).

\section{Acknowledgements}

We thank Changzhi Pu, Wenze Yang, Simin Lin and Xuelong Jiang for their assistance in samples collection.

\section{Authors' contributions}

This study was conceived by J.Z. and the project was led by J.Z., X.K. and L.N. Collection of the sample, mitogenomic data and references were done by J.Z., G.M., S.Y., Z.J. and P.G. Data analysis and the experiments were performed by J.Z., S.H., Q.S. X.K., H.D and C.W.. The manuscript was written by J.Z., S.H., Q.S. and Z.J. All authors read and approved the final manuscript.

\section{Funding}

This study was funded by National Natural Science Foundation of China (No. 31501461, 31800256); Anhui Science and Technology Major Project (No. 18030701189); Independent Research fund of Key Laboratory of Industrial Dust Prevention and Control \& Occupational Health and Safety, Ministry of Education (Anhui University of Science and Technology) (No. EK20201004), Huainan science and technology project (2017A0421); the Key Support Program for Outstanding Young Talents in University of Anhui Province (No. gxyqZD2016264); the Research Projects of Huainan Normal University (Nos. 2019hsjy22, 2017hsyxkc91, 2015xj49zd, 2015hssjjd05, and 2015hsyxkc22). The funding bodies had no role in the design of the study and collection, analysis, and interpretation of data and in writing the manuscript.

\section{Availability of data and materials}

The source code of qMGR was freely available under GNU GPL at https://githu b.com/zhanglab2019/qMGR, and its web service was available at http://qmgr. hnnu.edu.cn/. The four complete sequences of our newly identified frogs were submitted to GenBank (https://www.ncbi.nlm.nih.gov/) with accession numbers KY441640 (Q. robertingeri), AY899241 (L. fragilis), MF678821 (L. fujianensis (Taiwan)) and AY974191 (L. fujianensis (Fujian)), respectively. We downloaded sequences data of amphibian mitogenomes from NCBI: Organelle Genome Resource (http://www.ncbi.nlm.nih.gov/genome/organelle/).

\section{Ethics approval and consent to participate}

Frog experiments were conducted according to the guidelines established by the Regulations for the Administration of Affairs Concerning Experimental Animals (Ministry of Science and Technology, China, 2004). Our research was approved by the Animal Ethics Committee of Huainan Normal University (approval number: AE20151020). The collection of the samples was approved by the Academic Committee of Huainan Normal University and the corresponding local forestry management departments. The collection behavior complied with Regulation for the collection of genetic resources of China ( $\mathrm{HJ}$ 628-2011),

\section{Consent for publication}

Not applicable.

\section{Competing interests}

The authors declare that they have no competing interests.

\section{Author details}

${ }^{1}$ School of Biological Engineering, Huainan Normal University, Huainan, Anhui 232001, People's Republic of China. ${ }^{2}$ College of Life Science, Anhui Normal University, Wuhu, Anhui 241000, People's Republic of China. ${ }^{3}$ Anhui Key Laboratory of Low Temperature Co-Fired Materials, Huainan Normal University, Huainan 232001, People's Republic of China. ${ }^{4}$ Key Laboratory of Industrial Dust Prevention and Control and Occupational Health and Safety, Ministry of Education, Huainan 232001, People's Republic of China. ${ }^{5}$ Anhui Shanhe Pharmaceutical Excipients Co., Ltd., Huainan 232001, People's Republic of China. ${ }^{6}$ Department of Biostatistics, Bloomberg School of Public Health, Johns Hopkins University, Baltimore, MD 21205, USA. ${ }^{7}$ Life Science and Food Engineering College, Yibin University, Yibin, Sichuan 644000, People's Republic of China.

Received: 16 May 2020 Accepted: 28 January 2021

Published online: 09 February 2021

\section{References}

1. Boore JL. Animal mitochondrial genomes. Nucleic Acids Res. 1999;27(8):1767-80.

2. Sumida M, Kanamori Y, Kaneda H, Kato Y, Nishioka M, Hasegawa M, Yonekawa $\mathrm{H}$. Complete nucleotide sequence and gene rearrangement of 
the mitochondrial genome of the Japanese pond frog Rana nigromaculata. Genes Genet Syst. 2001;76(5):311-25.

3. Boore JL, Brown WM. Big trees from little genomes: mitochondrial gene order as a phylogenetic tool. Curr Opin Genet Dev. 1998;8(6):668-74.

4. Brown WM, George M Jr, Wilson AC. Rapid evolution of animal mitochondrial DNA. Proc Natl Acad Sci USA. 1979;76(4):1967-71.

5. Cummings MP, Meyer A. Magic bullets and golden rules: data sampling in molecular phylogenetics. Zoology. 2005;108(4):329-36.

6. Dellaporta SL, Xu A, Sagasser S, Jakob W, Moreno MA, Buss LW, Schierwater B. Mitochondrial genome of Trichoplax adhaerens supports placozoa as the basal lower metazoan phylum. Proc Natl Acad Sci USA. 2006;103(23):8751-6.

7. Anderson S, Bankier AT, Barrell BG, de Bruijn MH, Coulson AR, Drouin J, Eperon IC, Nierlich DP, Roe BA, Sanger F, et al. Sequence and organization of the human mitochondrial genome. Nature. 1981;290(5806):457-65.

8. Bibb MJ, Van Etten RA, Wright CT, Walberg MW, Clayton DA. Sequence and gene organization of mouse mitochondrial DNA. Cell. 1981;26(2 Pt 2):167-80. https://doi.org/10.1016/0092-8674(81)90300-7.

9. Roe BA, Ma DP, Wilson RK, Wong JF. The complete nucleotide sequence of the Xenopus laevis mitochondrial genome. J Biol Chem. 1985;260(17):9759-74

10. Zardoya R, Meyer A. The complete nucleotide sequence of the mitochondrial genome of the lungfish (Protopterus dolloi) supports its phylogenetic position as a close relative of land vertebrates. Genetics. 1996;142(4):1249-63.

11. Zhong J, Li G, Liu ZQ, Li QW, Wang YQ. Gene rearrangement of mitochondrial genome in the vertebrate. Yi chuan xue bao = Acta genetica Sinica. 2005;32(3):322-30.

12. Ki JS, Dahms HU, Hwang JS, Lee JS. The complete mitogenome of the hydrothermal vent crab Xenograpsus testudinatus (Decapoda, Brachyura) and comparison with brachyuran crabs. Comp Biochem Physiol D: Genomics Proteomics. 2009;4(4):290-9.

13. Kilpert F, Podsiadlowski L. The complete mitochondrial genome of the common sea slater, Ligia oceanica (Crustacea, Isopoda) bears a novel gene order and unusual control region features. BMC Genomics. 2006; $7: 241$

14. Kurabayashi A, Sumida M. Afrobatrachian mitochondrial genomes: genome reorganization, gene rearrangement mechanisms, and evolutionary trends of duplicated and rearranged genes. BMC Genomics. 2013;14:633.

15. Mindell DP, Sorenson MD, Dimcheff DE. Multiple independent origins of mitochondrial gene order in birds. Proc Natl Acad Sci USA. 1998:95(18):10693-7.

16. San Mauro D, Gower DJ, Zardoya R, Wilkinson M. A hotspot of gene order rearrangement by tandem duplication and random loss in the vertebrate mitochondrial genome. Mol Biol Evol. 2006;23(1):227-34.

17. Shi W, Gong L, Wang SY, Miao XG, Kong XY. Tandem duplication and random loss for mitogenome rearrangement in Symphurus (Teleost: Pleuronectiformes). BMC Genomics. 2015;16:355.

18. Lavrov DV, Boore JL, Brown WM. Complete mtDNA sequences of two millipedes suggest a new model for mitochondrial gene rearrangements: duplication and nonrandom loss. Mol Biol Evol. 2002;19(2):163-9.

19. Shi W, Dong XL, Wang ZM, Miao XG, Wang SY, Kong XY. Complete mitogenome sequences of four flatfishes (Pleuronectiformes) reveal a novel gene arrangement of L-strand coding genes. BMC Evol Biol. 2013;13:173.

20. Lunt DH, Hyman BC. Animal mitochondrial DNA recombination. Nature. 1997;387(6630):247.

21. Maarouf N, Arno G, Carter ND, Syrris P, Yusuf S, Camm AJ, Poleiniki J, Al-Saady NM. Quantification of mitochondrial sublimons in human fibrillating atria. Clin Sci. 2004;106(6):653-9.

22. Babbucci M, Basso A, Scupola A, Patarnello T, Negrisolo E. Is it an ant or a butterfly? Convergent evolution in the mitochondrial gene order of Hymenoptera and Lepidoptera. Genome Biol Evol. 2014;6(12):3326-43.

23. Basso A, Babbucci M, Pauletto M, Riginella E, Patarnello T, Negrisolo E. The highly rearranged mitochondrial genomes of the crabs Maja crispata and Maja squinado (Majidae) and gene order evolution in Brachyura. Sci Rep. 2017;7(1):4096.

24. Bernt $M$, Merkle D, Middendorf $M$. An algorithm for inferring mitogenome rearrangements in a phylogenetic tree. In: Comparative genomics, international workshop, RECOMB-CG 2008, Paris, France, October 13-15, 2008 Proceedings: 2008. Pp 143-157.
25. Bernt M, Merkle D, Ramsch K, Fritzsch G, Perseke M, Bernhard D, Schlegel M, Stadler PF, Middendorf M. CREx: inferring genomic rearrangements based on common intervals. Bioinformatics. 2007;23(21):2957-8.

26. Boore JL, Lavrov DV, Brown WM. Gene translocation links insects and crustaceans. Nature. 1998;392(6677):667-8.

27. Machado DJ, Lyra ML, Grant T. Mitogenome assembly from genomic multiplex libraries: comparison of strategies and novel mitogenomes for five species of frogs. Mol Ecol Resour. 2016;16(3):686-93.

28. Xia Y, Zheng Y, Miura I, Wong PB, Murphy RW, Zeng X. The evolution of mitochondrial genomes in modern frogs (Neobatrachia): nonadaptive evolution of mitochondrial genome reorganization. BMC Genomics. 2014;15:691.

29. Zhang JF, Nie LW, Wang Y, Hu LL. The complete mitochondrial genome of the large-headed frog, Limnonectes bannaensis (Amphibia: Anura), and a novel gene organization in the vertebrate mtDNA. Gene. 2009:442(1-2):119-27.

30. San Mauro D, Gower DJ, Cotton JA, Zardoya R, Wilkinson M, Massingham T. Experimental design in phylogenetics: testing predictions from expected information. Syst Biol. 2012;61(4):661-74.

31. Kurabayashi A, Usuki C, Mikami N, Fujii T, Yonekawa H, Sumida M, Hasegawa M. Complete nucleotide sequence of the mitochondrial genome of a Malagasy poison frog Mantella madagascariensis: evolutionary implications on mitochondrial genomes of higher anuran groups. Mol Phylogenet Evol. 2006;39(1):223-36.

32. Sano N, Kurabayashi A, Fujii T, Yonekawa H, Sumida M. Complete nucleotide sequence of the mitochondrial genome of Schlegel's tree frog Rhacophorus schlegelii (family Rhacophoridae): duplicated control regions and gene rearrangements. Genes Genet Syst. 2005;80(3):213-24.

33. Mueller RL, Boore JL. Molecular mechanisms of extensive mitochondrial gene rearrangement in plethodontid salamanders. Mol Biol Evol. 2005;22(10):2104-12

34. Xia Y, Zheng Y, Murphy RW, Zeng X. Intraspecific rearrangement of mitochondrial genome suggests the prevalence of the tandem duplicationrandom loss (TDLR) mechanism in Quasipaa boulengeri. BMC Genomics. 2016;17(1):965

35. Zhang J, Kan X, Miao G, Hu S, Sun Q, Tian W. qMGR: a new approach for quantifying mitochondrial genome rearrangement. Mitochondrion. 2020;52:20.

36. Chen G, Wang B, Liu J, Xie F, Jiang J. Complete mitochondrial genome of Nanorana pleskei (Amphibia: Anura: Dicroglossidae) and evolutionary characteristics. Curr Zool. 2011;57(6):785-805.

37. Shan $X$, Xia Y, Zheng YC, Zou FD, Zeng XM. The complete mitochondrial genome of Quasipaa boulengeri (Anura: Dicroglossidae). Mitochondrial DNA. 2014;25(2):83-4.

38. Feng YJ, Blackburn DC, Liang D, Hillis DM, Wake DB, Cannatella DC, Zhang P. Phylogenomics reveals rapid, simultaneous diversification of three major clades of Gondwanan frogs at the Cretaceous-Paleogene boundary. Proc Natl Acad Sci USA. 2017;114(29):E5864-70.

39. Roelants K, Gower DJ, Wilkinson M, Loader SP, Biju SD, Guillaume K, Moriau L, Bossuyt F. Global patterns of diversification in the history of modern amphibians. Proc Natl Acad Sci USA. 2007:104(3):887-92.

40. Hickerson MJ, Cunningham CW. Dramatic mitochondrial gene rearrangements in the hermit crab Pagurus longicarpus (Crustacea, anomura). Mol Biol Evol. 2000;17(4):639-44.

41. Mu X, Yang Y, Liu Y, Luo D, Xu M, Wei H, Gu D, Song H, Hu Y. The complete mitochondrial genomes of two freshwater snails provide new proteincoding gene rearrangement models and phylogenetic implications. Parasites Vectors. 2017:10(1):11.

42. Qian L, Wang H, Yan J, Pan T, Jiang S, Rao D, Zhang B. Multiple independent structural dynamic events in the evolution of snake mitochondrial genomes. BMC Genomics. 2018;19(1):354.

43. Pyron RA. Divergence time estimation using fossils as terminal taxa and the origins of Lissamphibia. Syst Biol. 2011;60(4):466-81.

44. Pyron RA, Wiens JJ. A large-scale phylogeny of Amphibia including over 2800 species, and a revised classification of extant frogs, salamanders, and caecilians. Mol Phylogenet Evol. 2011;61(2):543-83.

45. San Mauro D. A multilocus timescale for the origin of extant amphibians. Mol Phylogenet Evol. 2010;56(2):554-61.

46. Zhang P, Zhou H, Chen YQ, Liu YF, Qu LH. Mitogenomic perspectives on the origin and phylogeny of living amphibians. Syst Biol. 2005;54(3):391-400. 
47. Hoegg S, Vences M, Brinkmann H, Meyer A. Phylogeny and comparative substitution rates of frogs inferred from sequences of three nuclear genes. Mol Biol Evol. 2004;21(7):1188-200.

48. Roelants K, Bossuyt F. Archaeobatrachian paraphyly and pangaean diversification of crown-group frogs. Syst Biol. 2005;54(1):111-26.

49. Frost DR, Grant T, Faivovich J, Bain RH, Haas A, Haddad CFB, De Sa RO, Channing A, Wilkinson M, Donnellan SC. The amphibian tree of life. Bull Am Museum Nat History. 2006;297(297):1-370.

50. Irisarri I, San Mauro D, Abascal F, Ohler A, Vences M, Zardoya R. The origin of modern frogs (Neobatrachia) was accompanied by acceleration in mitochondrial and nuclear substitution rates. BMC Genomics. 2012;13:626.

51. Vieites DR, Zhang P, Wake DB. Salamanders (Caudata). The timetree of life 2009:365-368. https://www.google.com/books?hl=zh-CN\&lr=\&id=9rt1c $1 \mathrm{~h} / 49 \mathrm{MC} \& \mathrm{oi}=\mathrm{fnd} \& \mathrm{pg}=$ PA365\&ots $=$ PW-ES7dxzp\&sig $=$ YoUdZBYhl9 ICq3wyMok9cSEZbeE.

52. San Mauro D, Gower DJ, Müller H, Loader SP, Zardoya R, Nussbaum RA, Wilkinson M. Life-history evolution and mitogenomic phylogeny of caecilian amphibians. Mol Phylogenet Evol. 2014;73:177-89.

53. Haring E, Kruckenhauser L, Gamauf A, Riesing MJ, Pinsker W. The complete sequence of the mitochondrial genome of Buteo buteo (Aves, Accipitridae) indicates an early split in the phylogeny of raptors. Mol Biol Evol. 2001;18(10):1892-904.

54. Boore JL, Daehler LL, Brown WM. Complete sequence, gene arrangement, and genetic code of mitochondrial DNA of the cephalochordate Branchiostoma floridae (Amphioxus). Mol Biol Evol. 1999;16(3):410-8.

55. Dowton M, Campbell NJ. Intramitochondrial recombination-is it why some mitochondrial genes sleep around? Trends Ecol Evol. 2001;16(6):269-71.

56. Zhang J-Y, Zhang L-P, Yu D-N, Storey KB, Zheng R-Q. Complete mitochondrial genomes of Nanorana taihangnica and N. yunnanensis (Anura: Dicroglossidae) with novel gene arrangements and phylogenetic relationship of Dicroglossidae. BMC Evol Biol. 2018;18(1):1-13.

57. Liu ZQ, Wang YQ, Su B. The mitochondrial genome organization of the rice frog, Fejervarya limnocharis (Amphibia: Anura): a new gene order in the vertebrate mtDNA. Gene. 2005;346:145-51.

58. Alam MS, Kurabayashi A, Hayashi Y, Sano N, Khan MMR, Fujii T, Sumida M. Complete mitochondrial genomes and novel gene rearrangements in two dicroglossid frogs, Hoplobatrachus tigerinus and Euphlyctis hexadactylus, from Bangladesh. Genes Genet Syst. 2010;85(3):219-32.

59. Irisarri I, San Mauro D, Green DM, Zardoya R. The complete mitochondrial genome of the relict frog Leiopelma archeyi: insights into the root of the frog tree of life. Mitochondrial DNA. 2010;21(5):173-82.

60. Shi W, Miao X-G, Kong X-Y. A novel model of double replications and random loss accounts for rearrangements in the Mitogenome of Samariscus latus (Teleostei: Pleuronectiformes). BMC Genomics. 2014;15(1):352.

61. Satoh TP, Sato Y, Masuyama N, Miya M, Nishida M. Transfer RNA gene arrangement and codon usage in vertebrate mitochondrial genomes: a new insight into gene order conservation. BMC Genomics. 2010;11:479.

62. Bernt M, Merkle D, Middendorf M. An algorithm for inferring mitogenome rearrangements in a phylogenetic tree. In: Research in computational molecular biology. 2008; pp 143-157.

63. Bernt M, Merkle D, Middendorf M. Using median sets for inferring phylogenetic trees. Bioinformatics. 2007;23(2):129-35.

64. Moret BME, Siepel A, Tang J, Liu T. Inversion medians outperform breakpoint medians in phylogeny reconstruction from gene-order data. In: Workshop on algorithms in bioinformatics. 2002. 521-536.

65. Grant T, Frost DR, Caldwell JP, Gagliardo R, Haddad CFB, Kok PJR, Means DB, Noonan BP, Schargel WE, Wheeler WC. Phylogenetic systematics of dart-poison frogs and their relatives (amphibia: athesphatanura: dendrobatidae). Bull Am Museum Nat History. 2006;299:1-262.

66. San Mauro D, Gower DJ, Oommen OV, Wilkinson M, Zardoya R. Phylogeny of caecilian amphibians (Gymnophiona) based on complete mitochondrial genomes and nuclear RAG1. Mol Phylogenet Evol. 2004;33(2):413-27.

67. Irisarri I, Vences M, San Mauro D, Glaw F, Zardoya R. Reversal to air-driven sound production revealed by a molecular phylogeny of tongueless frogs, family Pipidae. BMC Evol Biol. 2011;11(1):114.

68. Eberhard JR, Wright TF. Rearrangement and evolution of mitochondrial genomes in parrots. Mol Phylogenet Evol. 2016;94:34-46.

69. Sano N, Kurabayashi A, Fujii T, Yonekawa H, Sumida M. Complete nucleotide sequence and gene rearrangement of the mitochondrial genome of the bell-ring frog, Buergeria buergeri (family Rhacophoridae). Genes Genet Syst. 2004;79(3):151-63.

70. Prada CF, Boore JL. Gene annotation errors are common in the mammalian mitochondrial genomes database. BMC Genomics. 2019;20(1):73.

71. Paabo S, Thomas WK, Whitfield KM, Kumazawa Y, Wilson AC. Rearrangements of mitochondrial transfer RNA genes in marsupials. J Mol Evol. 1991;33(5):426-30.

72. Macey JR, Larson A, Ananjeva NB, Fang Z, Papenfuss TJ. Two novel gene orders and the role of light-strand replication in rearrangement of the vertebrate mitochondrial genome. Mol Biol Evol. 1997;14(1):91-104.

73. Seutin G, Lang BF, Mindell DP, Morais R. Evolution of the WANCY region in amniote mitochondrial DNA. Mol Biol Evol. 1994;11(3):329-40.

74. Chen Z, Zhai X, Zhu Y, Chen X. Complete mitochondrial genome of the Ye's spiny-vented frog Yerana yei (Anura: Dicroglossidae). Mitochondrial DNA. 2015;26(3):489-90.

75. Bernt M, Donath A, Juhling F, Externbrink F, Florentz C, Fritzsch G, Putz J, Middendorf M, Stadler PF. MITOS: improved de novo metazoan mitochondrial genome annotation. Mol Phylogenet Evol. 2013;69(2):313-9.

76. Lowe TM, Eddy SR. tRNAscan-SE: a program for improved detection of transfer RNA genes in genomic sequence. Nucleic Acids Res. 1997;25(5):955-64.

77. Felsenstein J. Evolutionary trees from DNA sequences: a maximum likelihood approach. J Mol Evol. 1981;17(6):368-76.

78. Huelsenbeck JP, Ronquist F, Nielsen R, Bollback JP. Bayesian inference of phylogeny and its impact on evolutionary biology. Science. 2001;294(5550):2310-4

79. Katoh K, Standley DM. MAFFT multiple sequence alignment software version 7: improvements in performance and usability. Mol Biol Evol. 2013;30(4):772-80

80. Xia X. DAMBE7: new and improved tools for data analysis in molecular biology and evolution. Mol Biol Evol. 2018;35(6):1550-2.

81. Lanfear R, Frandsen PB, Wright AM, Senfeld T, Calcott B. PartitionFinder 2: new methods for selecting partitioned models of evolution for molecular and morphological phylogenetic analyses. Mol Biol Evol. 2016:34(3):772-3.

82. Ronquist F, Huelsenbeck JP. MrBayes 3: Bayesian phylogenetic inference under mixed models. Bioinformatics. 2003;19(12):1572-4

83. Ronquist F, Teslenko M, van der Mark P, Ayres DL, Darling A, Hohna S, Larget B, Liu L, Suchard MA, Huelsenbeck JP. MrBayes 3.2: efficient Bayesian phylogenetic inference and model choice across a large model space. Syst Biol. 2012;61(3):539-42.

84. Rambaut A, Drummond AJ, Xie D, Baele G, Suchard MA. Posterior summarization in Bayesian phylogenetics using Tracer 1.7. Syst Biol. 2018;67(5):901-4.

85. Stamatakis A. RAxML version 8: a tool for phylogenetic analysis and postanalysis of large phylogenies. Bioinformatics. 2014;30(9):1312-3.

86. Stamatakis A. Phylogenetic models of rate heterogeneity: a high performance computing perspective. In: Parallel and distributed processing symposium, 2006 IPDPS 2006 20th International: 2006. IEEE: 8 pp.

\section{Publisher's Note}

Springer Nature remains neutral with regard to jurisdictional claims in published maps and institutional affiliations. 